\title{
Regional Anesthesia and Pain
}

\section{Witnessed asystole during spinal anesthesia treated with atropine and ondansetron: a case report}

\author{
[Asystolie pendant la rachianesthésie traitée avec de l'atropine et de l'ondansétron: \\ une étude de cas]
}

Robert M. Martinek MD FRCPC

Purpose: To present a case of asystole during spinal anesthesia that responded to atropine and ondansetron and to discuss the possible pathophysiology with special emphasis on the Bezold-Jarisch reflex and the role of $5-\mathrm{HT}_{3}$ receptors in mediating bradycardia and sympathoinhibition.

Clinical features: A 50-yr-old, 97-kg, healthy male presented for elective left high tibial osteotomy. Spinal anesthesia was induced uneventfully at L3-4 with I I.25 mg of hyperbaric $0.75 \%$ bupivacaine and morphine $0.25 \mathrm{mg}$. Thirteen minutes after induction, the incision site was infiltrated with $20 \mathrm{~mL}$ of $0.5 \%$ bupivacaine with epinephrine $5 \mu \mathrm{g} \cdot \mathrm{mL}^{-1}$ for intraoperative hemostasis, resulting in an increase in heart rate from 74 to 90 beats. $\mathrm{min}^{-1}$. Three minutes after infiltration of the incision site, the patient's heart rate dropped to 48 beats $\cdot \mathrm{min}^{-1}$, accompanied by a blood pressure of $107 / 51$ $\mathrm{mmHg}, \mathrm{SpO}_{2} 97 \%$, and a sinus bradycardia on the electrocardiogram. The electrocardiographic complexes suddenly disappeared with loss of the pulse oximeter waveform. Pre-drawn atropine 0.6 $\mathrm{mg}$ iv and ondansetron $4 \mathrm{mg}$ iv were administered within seven seconds of the event. After an asystolic period of 30 to $40 \mathrm{sec}$, but before chest compressions were initiated, vital signs returned to normal with no other sequelae.

Conclusion: Exogenous epinephrine may have triggered the Bezold-Jarisch reflex and subsequent asystole. It is postulated that the combination of atropine and ondansetron may have played a key role in resuscitation by blocking the serotonergic and cholinergic receptors in the afferent and efferent limbs of this vagally-mediated reflex.

Objectif : Présenter un cas d'asystolie, survenue pendant la rachianesthésie, qui a réagit à l'atropine et à l'ondansétron, et discuter de la physiopathologie possible en insistant sur le réflexe Bezold-Jarisch et sur le rôle des récepteurs de $5-\mathrm{HT}_{3}$ comme médiateurs de la bradycardie et de la sympatho-inhibition.

Éléments cliniques: Un homme de 50 ans, de $97 \mathrm{~kg}$ et en bonne santé, devait subir une ostéotomie tibiale gauche réglée. La rachianesthésie a été induite sans problème au niveau L3-4 avec II,25 $\mathrm{mg}$ de bupivacaïne hyperbare à $0,75 \%$ et $0,25 \mathrm{mg}$ de morphine. Treize minutes après l'induction, le site de l'incision a été infiltré avec $20 \mathrm{~mL}$ de bupivacaïne à $0,5 \%$ et de l'épinéphrine à raison de 5 $\mu \mathrm{g} \cdot \mathrm{mL}^{-1}$ pour l'hémostase peropératoire, ce qui a provoqué une élévation de la fréquence cardiaque de 74 à 90 battements $\cdot \mathrm{min}^{-1}$. Trois minutes après l'infiltration, la fréquence cardiaque a chuté à 48 battements $\cdot \mathrm{min}^{-1}$. On notait aussi une tension artérielle de 107/51 $\mathrm{mmHg}$, une $\mathrm{SpO}_{2}$ à $97 \%$ et une bradycardie sinusale à l'électrocardiogramme. Les complexes électrocardiographiques ont disparu soudainement avec la perte des ondes à l'oxymètre de pouls. Les doses de 0,6 mg d'atropine iv et de 4 mg d'ondansétron iv ont été administrées en moins de sept secondes suivant l'incident. Après une période asystolique de 30 à $40 \mathrm{~s}$, mais avant le début des compressions thoraciques, les signes vitaux sont revenus à la normale sans autre conséquence.

Conclusion : L'épinéphrine exogène a pu déclencher le réflexe de Bezold-Jarisch et l'asystolie subséquente. On croit que la combinaison d'atropine et d'ondansétron a pu jouer un rôle clé dans la réanimation en bloquant les récepteurs sérotoninergiques et cholinergiques des branches afférentes et efférentes de ce réflexe à médiation vagale.

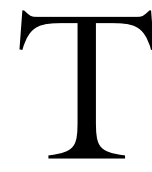

HE risk of sudden cardiac arrest in healthy patients during spinal anesthesia is well documented ${ }^{1-4}$ with a quoted incidence of seven per 10,000 spinal anesthetics. ${ }^{4,5}$

From the Department of Anesthesia, Brantford General Hospital, Brantford, Ontario, Canada.

Address correspondence to: Dr. Robert Martinek, Brantford General Hospital, 200 Terrace Hill Street, Brantford, Ontario N3R 1G9,

Canada. Fax: 519-751-2658; E-mail: dr.martinek@sympatico.ca

Accepted for publication April 10, 2003.

Revision accepted November 13, 2003.

CAN J ANESTH 2004/51:3/pp 226-230 
Pollard noted that the ASA closed claims database recorded 170 claims involving cardiac arrests during spinal or epidural anesthesia; $90 \%$ of these cases resulted in brain damage or death. ${ }^{6}$ The number of claims surpassed the 154 claims involving aspiration related injury. In recent reviews of the etiology of arrests under spinal anesthesia, the Bezold-Jarisch reflex (BJR) is one of the mechanisms implicated. ${ }^{1-8}$ In some animals the BJR can be abolished with $5-\mathrm{HT}_{3}$ antagonists. ${ }^{9-11}$

Current recommendations to treat asystole during spinal block include immediate restoration of volume by gravity or fluid bolus, early use of atropine, ephedrine, epinephrine, vasopressin, and thump pacing. The early use of epinephrine and volume restoration (and the relative inefficacy of atropine) have been emphasized previously. ${ }^{4-8,12}$

The following is a case of witnessed asystole during spinal anesthesia treated with a combination of iv atropine and ondansetron.

\section{Case report}

A 50-yr-old, 97-kg, healthy male presented for elective left high tibial osteotomy. He took omeprazole daily and denied any history of allergies, palpitations, or syncope. Preoperative examination was normal with a heart rate (HR) of 80 beats. $\mathrm{min}^{-1}$ and blood pressure $(\mathrm{BP})$ of $135 / 83 \mathrm{mmHg}$. The electrocardiogram (ECG) showed a sinus rhythm at 73 beats. $\mathrm{min}^{-1}$ with normal PR and QT intervals.

Following volume loading with lactated Ringer's $500 \mathrm{~mL}$ and sedation with iv remifentanil $25 \mu \mathrm{g}$, spinal anesthesia was induced at L3 -4 with hyperbaric $0.75 \%$ bupivacaine $11.25 \mathrm{mg}$ and morphine $0.25 \mathrm{mg}$. Vital signs were normal (HR 70 beats. $\mathrm{min}^{-1}$, systolic BP $130 \mathrm{mmHg}$ ). Thirteen minutes after induction, the surgeon injected the incision site with $20 \mathrm{~mL}$ of $0.5 \%$ bupivacaine with epinephrine $5 \mathrm{ug} \cdot \mathrm{mL}^{-1}$ for intraoperative hemostasis. Over the next three minutes, the HR increased from 74 to 90 beats. $\mathrm{min}^{-1}$. The patient stated that he was relaxed. He was supine and his lower extremities remained horizontal. Surgery had not commenced.

One minute later, the patient's HR suddenly dropped from 92 to 48 beats. $\mathrm{min}^{-1}$. The $\mathrm{BP}$ was $107 / 51 \mathrm{mmHg}, \mathrm{SpO}_{2}$ was $97 \%$, and the ECG showed a sinus bradycardia. The patient repeated that he felt fine. Atropine and ondansetron were drawn up and the atropine syringe was inserted into the iv tubing. Suddenly, while the author was watching the monitor, the ECG complex and pulse oximeter waveform disappeared. Atropine $0.6 \mathrm{mg} i v$ was given, followed immediately by ondansetron $4 \mathrm{mg} i v$. Both drugs were given within seven seconds. Near the end of drug administration, the patient lost consciousness and one breath of $100 \% \mathrm{O}_{2}$ was given by mask. After a total asystolic period of 30 to $40 \mathrm{sec}$, but before chest compressions were initiated, a HR of 96 beats. $\mathrm{min}^{-1}$ was registered by the pulse oximeter and confirmed by palpation.

The patient regained full consciousness and denied any chest pain, dyspnea, nausea, paresthesia, or tinnitus. His initial BP was $151 / 80 \mathrm{mmHg}$. The ECG showed a sinus rhythm without ST changes and a rate of 84 beats. $\mathrm{min}^{-1}$, which did not increase further. Pupil size and grip strength were normal. Sensory block to ice extended to the T6 dermatome bilaterally. The patient remained hemodynamically stable $(\mathrm{HR}>69$ beats. $\mathrm{min}^{-1}$, systolic $\mathrm{BP}>110 \mathrm{mmHg}$ ) without the use of vasopressors. The surgery was performed uneventfully under spinal anesthesia. The postoperative ECG was normal. Tilt-table testing was suggested for followup but the patient declined further investigations.

\section{Discussion}

Although the pathophysiology of asystole during spinal anesthesia is poorly understood, the pattern observed is very similar to the sudden bradycardia and circulatory collapse seen with vasovagal (neurocardiogenic) syncope, or severe volume depletion. ${ }^{7,8}$ The initial response to hypovolemia is a compensatory phase with an increased HR and vasoconstriction. However, after a critical reduction of central volume, a sudden decompensatory phase characterized by bradycardia and profound sympathetic withdrawal can occur. ${ }^{13}$ Thus, some hypovolemic patients may present with bradycardia, and further decreased preload can precipitate classic syncope or asystole. ${ }^{4-8,14}$ The decrease in preload caused by spinal anesthesia may initiate vagally-mediated cardiodepressor reflexes such as the BJR with resulting bradycardia and sympathoinhibition. Furthermore, sympathetic blockade from the spinal anesthetic with resulting vagal predominance and inhibition of compensatory vasoconstriction may exacerbate the problem. ${ }^{3-8}$

The BJR originally referred to bradycardia, hypotension, and apnea caused by the $i v$ injection of veratrum alkaloids. The cardiac and respiratory effects were found to be mediated via cardiac and pulmonary vagal afferents respectively. Later, bradycardia and hypotension from the stimulation of cardiac chemoreceptors and mechanoreceptors were established. ${ }^{7,8,15}$ Cardiac vagal afferents are located mainly in the inferoposterior wall of the left ventricle ${ }^{1}$ but are present in all cardiac chambers. ${ }^{15}$ Stimulation of these receptors increases parasympathetic activity and inhibits sympathetic activity producing bradycardia, vasodilation, hypotension, 
and inhibition of renal sympathetic activity. ${ }^{11,16}$ The reflex can be abolished by cervical vagotomy and the bradycardia can be blocked with anticholinergic drugs, but the efferent pathway of the sympathoinhibition remains unknown. ${ }^{8,17}$ The mechanoreceptors are normally triggered by distention. However, a decrease in venous return in combination with an increased inotropic state may deform the cardiac wall sufficiently to trigger the mechanically sensitive receptors in the same way as stretching and initiate a paradoxical vasodepressor response. ${ }^{1,8}$ Since a BJR-like reflex causing syncope has been shown in cardiac transplant patients, non-cardiac peripheral triggers and other mechanisms may also be involved. ${ }^{7,8,18}$

Head-up tilt (HUT) testing is used to simulate hypovolemia and can precipitate the BJR in susceptible individuals. ${ }^{18,19}$ When HUT fails to elicit syncope, isoproterenol may be used to provoke the response. Conversely, beta blockers have been used successfully to prevent subsequent syncopal episodes in these patients. ${ }^{19}$ The sitting position can cause venous pooling similar to a HUT test, and the BJR has been implicated as a cause of significant bradycardia and hypotension in patients undergoing shoulder arthroscopy under interscalene block. ${ }^{19}$ In Liguori's prospective study, prophylactic metoprolol given after the interscalene block reduced the incidence of these episodes from $28 \%$ to $5 \%$, suggesting that unopposed beta-adrenergic effects of epinephrine may play a role in the development of this reflex. ${ }^{19}$ In animals, exogenous epinephrine has been noted to augment the BJR induced by veratridine. ${ }^{15}$ In addition, significantly elevated epinephrine levels preceding syncope have been demonstrated in susceptible individuals during tilttable testing. ${ }^{20}$ Hence, the combination of hypovolemia and increased plasma epinephrine levels appear to be associated with imminent neurocardiogenic syncope in susceptible individuals.

Serotonin (5-HT) has been implicated in the pathogenesis of sympathoinhibition, both centrally via $5-\mathrm{HT}_{1}$ and $5-\mathrm{HT}_{2}$ receptors and peripherally via 5$\mathrm{HT}_{3}$ receptors. ${ }^{10,16-18,21,22}$ Direct stimulation of the cardiac $5-\mathrm{HT}_{3}$ chemoreceptors located on cardiac vagal afferents with $5-\mathrm{HT}$ or with $5-\mathrm{HT}_{3}$ agonists will elicit the BJR in several mammals. ${ }^{9,11}$ Conversely, in rats, epicardial injection of the $5-\mathrm{HT}_{3}$ antagonist MDL 72222 has been shown to completely abolish the reflex. ${ }^{16}$ Pretreatment with iv ondansetron (a 5$\mathrm{HT}_{3}$ antagonist) also abolished the BJR even when scorpion venom was used to augment the initial reflex. ${ }^{21}$ Furthermore, in a hemorrhagic rabbit model, granisetron was effective at preventing inappropriate HR slowing and allowed significantly more blood to be removed before reaching the target $\mathrm{BP}$ compared to the saline control. ${ }^{10}$ Interestingly, non-cardiac 5$\mathrm{HT}_{3}$ receptors have been demonstrated also in the rat lung, ${ }^{23}$ gastrointestinal mucosa ${ }^{24}$ and rabbit carotid sinus. ${ }^{25}$ All could be blocked with $5-\mathrm{HT}_{3}$ antagonists to prevent bradycardia and hypotension induced by 5 HT or phenyl biguanide (a $5-\mathrm{HT}_{3}$ agonist). Taken together these animal studies clearly demonstrate a role for peripheral $5-\mathrm{HT}_{3}$ receptors in producing bradycardia and sympathoinhibition.

Serotonin released during low-volume or ischemic states has been suggested as a possible trigger for the BJR. ${ }^{11,16,22}$ Activated platelets appear to be a source of 5-HT in animal models ${ }^{23,25,26}$ and epinephrine is well known to activate platelets. In some volunteers it has been demonstrated that catecholamine levels were elevated and platelets were depleted of their 5-HT content, suggesting that elevated concentrations of circulating catecholamines may induce platelet activation and 5-HT release. ${ }^{27}$ Interestingly, in a rabbit fat embolism model, pretreatment with a $5-\mathrm{HT}_{3}$ antagonist, cervical vagotomy, or antibody-induced thrombocytopenia prevented the usual hypotension and bradycardia. The survival rate reached $100 \%$ in the MDL 72222 group vs $25 \%$ in the saline group. ${ }^{23}$ If this applies to humans as well, $5-\mathrm{HT}_{3}$ chemoreceptor stimulation by release of 5 -HT from platelets may explain the sudden bradycardia and hypotension sometimes seen during cemented hip arthroplasty (often done under spinal anesthesia), and 5- $\mathrm{HT}_{3}$ antagonists may have a potential therapeutic role.

Although animal studies strongly support a role for $5-\mathrm{HT}_{3}$ antagonists in preventing the $\mathrm{BJR}$, limited human data appear less promising. In one study, iv granisetron decreased the change in HR and prevented recurrence of tilt-table syncope in $47 \%$ of 17 patients but did not alter the time to syncope or presyncope. ${ }^{28}$ In another study $(n=7)$ ondansetron did not alter the time to syncope, HR or BP changes during HUT. ${ }^{29}$ One case report described a patient with a thoracic epidural anesthetic who was given ondansetron $4 \mathrm{mg}$ iv for nausea yet still developed sudden bradycardia and asystole 15 min later. ${ }^{30}$ On the other hand, ondansetron and cardiac $5-\mathrm{HT}_{3}$ blockade has been implicated as a possible cause of tachycardia, hypertension and ischemia. ${ }^{31}$ Hence in humans, the role of $5-\mathrm{HT}_{3}$ antagonists in preventing bradycardia and sympathoinhibition is unclear.

In this patient, the BJR, triggered by epinephrine, could explain the observed sequence of events. The immediate drop in HR, followed by asystole, is consistent with a cardiac reflex. The rapid resolution without any residual sequelae also supports a reflex 
mechanism. The initial rise in HR shortly after the injection of bupivacaine with epinephrine, in the absence of any obvious emotional or surgical stimuli, suggests beta-adrenergic stimulation from systemic absorption of epinephrine. Increased cardiac contractility from epinephrine combined with central hypovolemia from the spinal block, may have initiated the BJR via the cardiac mechanoreceptors. Alternatively, epinephrine may have caused endogenous 5-HT release, triggering the cardiac (or non-cardiac) chemoreceptors. Furthermore, low-dose epinephrine could have aggravated hypovolemia by shunting more blood to the muscle and viscera (beta ${ }_{2}$ effect) and could explain the rapidity of the observed HR changes. Increasing vagal tone from stimulation of vagal afferent receptors may have initiated the sudden HR drop and, as hypovolemia and cardiac contractility increased, ultimately resulted in asystole. In retrospect, atropine should have been given during the initial bradycardia even though the BP was still stable at the time. The reversal of asystole and subsequent hemodynamic stability, without additional fluid volume suggests that the BJR was successfully inhibited following administration of atropine and ondansetron.

A vagally-mediated cardiodepressor reflex appears to be the best explanation of events. The hypothesis assumes the initial rise in HR was due to the betaadrenergic effects of systemically absorbed epinephrine, but since plasma levels were not measured the cause remains speculative. Although a slight rise in HR may be seen in the compensatory phase of hypovolemia during tilt-testing, ${ }^{18}$ a period of bradycardia usually precedes cardiac arrest in patients under spinal anesthesia. ${ }^{4,5}$, The augmentation of the BJR by exogenous epinephrine could explain the sudden (rather than gradual) onset of bradycardia. Bupivacaine toxicity does not appear to have played a role since there were no central neurological sequelae or ventricular arrhythmias and the asystole resolved rapidly. Spontaneous reversal of the asystole is a possible explanation; however, tachycardia would have been expected once the atropine had reached its effector sites. The HR and BP increased immediately after the asystole resolved and remained stable for the duration of the case, implying that atropine (and ondansetron) had reached their effector sites. Since both drugs were given rapidly, the iv was running well, and there would be an initial venous pressure gradient to wind down, sufficient venous flow to deliver the drugs to the right heart without chest compressions was presumed.

Although atropine alone has been used to treat these cardiac arrests, ${ }^{1,30}$ it is usually given with ephedrine or epinephrine in successfully treated cases. ${ }^{1-3,12}$ Atropine can reverse the bradycardia but may fail to prevent the drop in BP and syncope caused by the sudden withdrawal of sympathetic tone. . $^{5,8,13,22}$ Santagostino reported two patients who arrested under spinal anesthesia despite the use of atropine $(0.7 \mathrm{mg}$ and $1.0 \mathrm{mg}) .{ }^{12} \mathrm{He}$ specifically commented on the efficacy of epinephrine and the relative inefficacy of atropine. Liguori et al. ${ }^{19}$ compared glycopyrrolate or metoprolol in preventing bradycardia and hypotension in the sitting position, and showed only a minimal decrease in incidence with the use of an anticholinergic compared to placebo ( $22 \%$ vs $28 \%)$. Other than the atropine, none of the other recommended treatments for spinal cardiac arrests were used. Specifically, no vasopressors or additional fluid volume were required to restore a normal BP. In the absence of other interventions, ondansetron, via its $5-\mathrm{HT}_{3}$ antagonism, may have been therapeutic in this patient.

In summary, the asystole in this patient could be explained by exogenous epinephrine triggering the BJR. Ondansetron may have antagonized the afferent vagal $5-\mathrm{HT}_{3}$ receptors sufficiently to block the reflex. The concomitant use of atropine and its anticholinergic action on the efferent vagal limb of this reflex may have played a key role as well. Hence it is postulated that the afferent and efferent limbs of the vagally-mediated BJR may be significantly blocked by combined serotonergic and cholinergic receptor blockade. The role, if any, of ondansetron during cardiac arrest under spinal anesthesia in humans requires further study.

\section{Acknowledgements}

The author would like to thank Dr. Peter Choi for his comments on the revised manuscript, Dr. Homer Yang and Dr. Barry Finegan for their encouragement during the draft stage, and Barbara Gray and Dawn Bombay for obtaining many of the background articles. Special thanks to Laurie Martinek for her support during the preparation of this manuscript.

\section{References}

1 Mackey DC, Carpenter RL, Thompson GE, Brown DL, Bodily $M N$. Bradycardia and asystole during spinal anesthesia: a report of three cases without morbidity. Anesthesiology 1989; 70: 866-8.

2 Liguori GA, Sharrock NE. Asystole and severe bradycardia during epidural anesthesia in orthopedic patients. Anesthesiology 1997; 86: 250-7.

3 Geffin B, Shapiro L. Sinus bradycardia and asystole during spinal and epidural anesthesia: a report of 13 cases. J Clin Anesth 1998; 10: 278-85.

4 Pollard JB. Cardiac arrest during spinal anesthesia: common mechanisms and strategies for prevention. 
Anesth Analg 2001; 92: 252-6.

5 Moemen ME. The fatal spinal. Eg J Anesth 2002; 18 : 133-41.

6 Pollard JB. Common mechanisms and strategies for prevention and treatment of cardiac arrest during epidural anesthesia. J Clin Anesth 2002; 14: 52-6.

7 Stienstra R. Mechanisms behind and treatment of sudden, unexpected circulatory collapse during central neuraxis blockade. Acta Anaesthesiol Scand 2000; 44: 965-71.

8 Kinsella SM, Tuckey JP. Perioperative bradycardia and asystole: relationship to vasovagal syncope and the Bezold-Jarisch reflex. Br J Anaesth 2001; 86: 859-68.

9 Yamano $M$, Ito $H$, Kamato T, Miyata K. Species difference in the 5-hydroxytryptamine ${ }_{3}$ receptor associated with the von Bezold-Jarisch reflex. Arch Int Pharmacodyn Ther 1995; 330: 177-89.

10 White CM, Chow MS, Fan C, Kluger J, Bazunga M. Efficacy of intravenous granisetron in suppressing the bradycardia and hypotension associated with a rabbit model of the Bezold-Jarisch reflex. J Clin Pharmacol 1998; 38: 172-7.

11 Veelken $R$, Hilgers $K F$, Leonard $M$, et al. A highly selective cardiorenal serotonergic $5-\mathrm{HT}_{3}$-mediated reflex in rats. Am J Physiol 1993; 264(6 Pt 2): H1871-7.

12 Santagostino G, Messeri E, Morelli M, Gambi D. Two cases of asystole during selective spinal anaesthesia (Italian). ALR 1995; 4: 232-8.

13 Secher NH, Bie P. Bradycardia during reversible haemorrhagic shock - a forgotten observation? Clin Physiol 1985; 5: 315-23.

14 Baron-Esquivias $G$, Pedrote $A$, Cayuela $A$, et al. Longterm outcome of patients with asystole induced by head-up tilt test. Eur Heart J 2002; 23: 483-9.

15 Thoren $P$. Role of cardiac vagal C-fibers in cardiovascular control. Rev Physiol Biochem Pharmacol 1979; 86: $1-94$.

16 Veelken R, Sawin LL, DiBona GF. Epicardial serotonin receptors in circulatory control in conscious SpragueDawley rats. Am J Physiol 1990; 258(2 Pt 2): H466-72.

17 Grubb BP, Karas BJ. The potential role of serotonin in the pathogenesis of neurocardiogenic syncope and related autonomic disturbances. J Interv Card Electrophysiol 1998; 2: 325-32.

18 Matzen SH. Neuroendocrine mechanisms during reversible hypovolaemic shock in humans with emphasis on the histaminergic and serotonergic system. Acta Physiol Scand Suppl 1995; 628: 1-31.

19 Liguori GA, Kahn RL, Gordon J, Gordon MA, Urban $M K$. The use of metoprolol and glycopyrrolate to prevent hypotensive/bradycardic events during shoulder arthroscopy in the sitting position under interscalene block. Anesth Analg 1998; 87: 1320-5.

20 Benditt DG, Ermis C, Padanilam B, Samniah N, Sakaguchi $S$. Catecholamine response during haemodynamically stable upright posture in individuals with and without tilt-table induced vasovagal syncope. Europace 2003; 5: 65-70.

21 Bagchi S, Deshpande SB. Indian red scorpion (Buthus tamulus) venom-induced augmentation of cardiac reflexes is mediated through the involvement of peripheral 5- $\mathrm{HT}_{3}$ and central $5-\mathrm{HT}_{1 \mathrm{~A}}$ receptor subtypes. Toxicon 1999; 37: 1697-709.

22 White CM, Tsikouris JP. A review of pathophysiology and therapy of patients with vasovagal syncope. Pharmacotherapy 2000; 20: 158-65.

23 Leanos OL, Hong E, Amezcua JL. Reflex circulatory collapse following intrapulmonary entrapment of activated platelets: mediation via $5-\mathrm{HT}_{3}$ receptor stimulation. Br J Pharmacol 1995; 116: 2048-52.

24 Uneyama H, Niijima A, Tanaka T, Torii K. Receptor subtype specific activation of the rat gastric vagal afferent fibers to serotonin. Life Sci 2002; 72: 415-23.

25 Mao HZ, Li Z, Chapleau MW. Platelet activation in carotid sinuses triggers reflex sympathoinhibition and hypotension. Hypertension 1996; 27(3 Pt 2): 584-90.

26 Wiggins RC, Glatfelter A, Campbell AM, Kunkel RG, Ulevitch RJ. Acute hypotension due to platelet serotonin-induced chemoreflexes after intravenous injection of dextran sulfate in the rabbit. Circ Res 1985; 57 : 262-77.

27 Palermo A, del Rosso G, Costantini C, Bertalero P, Rizzi S, Libretti A. Platelet content of serotonin and response to stress. J Hypertens Suppl 1986; 4: S43-5.

28 Tsikouris JP, Kluger J, Chow MS, White CM. Usefulness of intravenous granisetron for prevention of neurally mediated hypotension upon head upright tilt testing. Am J Cardiol 2000; 85: 1262-4.

29 Matzen S, Secher NH, Knigge U, et al. Effect of serotonin receptor blockade on endocrine and cardiovascular responses to head-up tilt in humans. Acta Physiol Scand 1993; 149: 163-76.

30 Chan KM, Welch KJ. Cardiac arrest during segmental thoracic epidural anesthesia. Anesthesiology 1997; 86: 503-5.

31 Bosek V, Hu P, Robinson LA. Acute myocardial ischemia after administration of ondansetron hydrochloride. Anesthesiology 2000; 92: 885-7. 